\title{
Simple Hierarchy Analysis-Based Linguistic Weights to Effective Teaching Evaluation
}

\author{
Zamali Tarmudi ${ }^{1}$, Munirah Rossdy ${ }^{2}$, Jasman Jaafar ${ }^{3}$, Abdul Kadir Rosline ${ }^{4}$, \\ ${ }^{1,2}$ (Faculty of Computer and Mathematical Sciences, Universiti Teknologi MARA Sabah, Locked Bag 71, 88997 \\ Kota Kinabalu, Sabah, Malaysia) \\ ${ }^{3}$ (Academy of Language Studies, Universiti Teknologi MARA Sabah, Locked Bag 71, 88997 Kota Kinabalu, \\ Sabah, Malaysia) \\ ${ }^{4}$ (Faculty of Administrative Science and Policy Studies, Universiti Teknologi MARA Sabah, Locked Bag 71, \\ 88997 Kota Kinabalu, Sabah, Malaysia)
}

\begin{abstract}
It has been observed that most of the criteria considered for gauging effective teaching for the lecturers' evaluation process are naturally imprecise, vague, qualitative, and involve varied input datasets. Besides that, these criteria are usually determined by the universities themselves without considering the perspective of their students. Thus, this study proposes that a lecturer's evaluation should also be investigated based on the students' perspectives. The study was equipped with the appropriate linguistic weights to cope with the vagueness of the input datasets using the so-called Simple Hierarchy Analysis (SHA). A numerical example was employed to demonstrate the applicability of the proposed method. Based on the result of the calculation, the method is shown to have great potential in dealing with the complexities in assessing lecturers' effectiveness in teaching. It offers a versatile judgment, has a clear procedures and is successful in dealing with both perspectives (i.e., students and universities) which are diversified and too ill-defined in terms of input criterion. With these characteristics, the proposed method can assist the universities' decision makers (DM's) in conducting the evaluation process in a simple and systematic manner.
\end{abstract}

Keywords: Concentration, Decision-Making, Effective Teaching, Linguistic Weights, Simple Hierarchy Analysis (SHA)

\section{Introduction}

Globally, there has been a steady increase in support for the sentiment that public universities in Malaysia must adopt a comprehensive technique or versatile method to evaluate the lecturers based on the students' perspective. This is because the students have their own views and evaluation of their own lecturers. Lecturers who deliver effective teaching will provide satisfaction in terms of learning and teaching process in the classroom. Effective teaching improves the quality of learning and helps produce high quality graduates. Generally, evaluation of the academic staff is a crucial process in a university. The evaluation process must be carried out properly and carefully, as it involves an investigation of the lecturers' credibility and capabilities which are in the interest of the development of a university. In light of this realization, this paper focuses on this exercise based on the students' perspective [1] using fuzzy linguistic variables weight. Inputs from students are very important as the main clients of the university and a key factor in improving the productivity of lecturers' teaching.

Effective teaching is closely related to the education and career of the lecturers. Various studies have been conducted which involved several methods in the evaluation process. Among the methods identified is to solve the staff evaluation problem using verbal information and genetic algorithm by providing a specific satisfactory algorithm [2]. It has been demonstrated that the appropriate application of this model could be employed and help to solve the staff evaluation problem. This method suggests that staff evaluation must also take into account the character, personality and the ability of the candidate. Next, Zulal et al. [3] stated that the evaluation of personalities and skills among the staff must be measured using qualitative and quantitative datasets. They proposed a system to evaluate the character of candidates using the so-called Fuzzy Analytic Hierarchy Process (FAHP).

Recent development has shown that the fuzzy applications have been increasingly employed by many researchers. However, the method does not only focus on evaluating the staff, it can be extended to other the evaluation of other issues and areas such as applications in the business and tourism industry. Some of the studies have utilized the Fuzzy TOPSIS (Technique for Order Fuzzy Preference by Similarity to Ideal Solution of) and Fuzzy AHP (Analytic Hierarchy Process Fuzzy) to assist in evaluating good suppliers to a company [4]. The same method was also applied to a manager's evaluation for appointment to a company's leadership position [5]. They also extended the use of the method to determine an appropriate project for a company's evaluation purposes. Other than that, fuzzy objectives with imprecise priorities combined with goal 
programming method have also been explored to evaluate the progress of a project [6]. This proposed approach was used to solve real life problems characterized as a Multi-Objective Project Selection with Multi-Period Planning Horizon (MOPS-MPPH). Meanwhile, in the tourism and hotel industry, the fuzzy approach has been used to select and evaluate the best hotels available in the study area [7] and to forecast tourist arrivals [8].

Furthermore, the hybrid fuzzy method can also be applied for evaluation purposes. For instance, Huu et al. [9], evaluated the demand of machine tools in manufacturing companies. They used a combination of Fuzzy ANP (Analytic Network Process) and COPRAS-G (Complex Assessment of proportional Toggle with Grey relations) to evaluate the machines and consider the various types of available attributes. Other methods such as the AHP were used to evaluate the most suitable location for company to run the businesses [10].

In a similar study, Norddin et al.[11] had utilised the AHP method to evaluate lecturers based on qualitative and quantitative datasets. At the faculty level for instance, the same method could be used in the selection and evaluation of deans [12]. The order and ranking concept was used to identify the most qualified candidate based on discussions among their committee members. It was concluded that the AHP was a valuable tool which should be incorporated in the process of an academician's evaluation.

From the literature, it has been shown that various applications have utilized the fuzzy approach to evaluate many problems in the workplace. However, established researchers have rarely explored lecturers' assessment, specifically in their effectiveness in teaching, based on the students' perspective. Thus, in this paper we propose a fuzzy approach using Simple Hierarchy Analysis (SHA) - based linguistic weights for effective teaching evaluation. This study also offers an alternative approach to existing conventional methods and at the same time provides specific criteria based on the students' perspective. To do so, this paper is structured as follows: Section 2 briefly discusses the problem statement; Section 3 and 4 both discuss the background theory and the implementation for illustration purposes, respectively; and finally, in Section 5 presents the conclusion.

\section{Problem Identification}

Most of the recent studies placed little focus on students' perspective in gauging the effectiveness of teaching. An effective delivery can make the students interested in the subject. In addition, the students will find it easier to understand what is conveyed in the classroom. In this study we evaluated the teaching effectiveness of lecturers based on students' feedback or perspective [1]. The Simple Hierarchy Analysis (SHA)-based linguistic weights were used in the evaluation process. We believe taking into account the views of students in the teaching evaluation process will help to identify problem areas to help administrators and the lecturers themselves improve the quality of the teaching and learning activities in the classroom.

\subsection{Preliminaries}

\section{The Basic Concept and Proposed Method}

For reference purposes, the theoretical background, basic definitions and the concepts of fuzzy sets will be used throughout this paper unless otherwise stated.

Definition 1 A fuzzy set A in a universe of discourse $X$ is characterized by a membership function $\mu_{\mathrm{A}}(x)$ that takes the values in the interval of [0,1]. It can be expressed as follows:

$$
\mathrm{A}=\left\{\left(\mu_{\mathrm{A}}(x) / x\right) ; x \in X\right\}
$$

Definition 2 A triangular fuzzy number (TFN) $\tilde{A}$ can be defined by a triplet $(a, b, c)$. The membership function $\mu_{\sim}(x)$ is defined as:

$$
\mu_{\tilde{A}}(x)=\left\{\begin{array}{cc}
0, & x<a, \\
\frac{x-a}{b-a}, & a \leq x \leq b, \\
\frac{x-c}{b-c}, & b \leq x \leq c, \\
0, & x>c
\end{array}\right.
$$

Definition 3 A linguistic hedge or a modifier is an operation that modifies the meaning of a term of a fuzzy set more generally. If $\tilde{A}$ is a fuzzy set then the modifier $k$ generates the (composite) term $\tilde{B}=k(\tilde{A})$.

The modifier used is: 


$$
\text { Concentration } \mu_{\operatorname{con}(\tilde{A})}(x)=\left[\mu_{\tilde{A}}(x)\right]^{w} \text {, where } \mathrm{w}>1
$$

Definition 4 The linguistic hedges and their approximate meanings are specifically classified as shown in Table 1.

Table 1: The hedge values of the specific concentration

\begin{tabular}{l|l|l}
\hline \multicolumn{1}{c|}{ Linguistic hedges } & \multicolumn{1}{c}{ Meaning } & Hedge values $(w)$ \\
\hline Extremely Important $(E I)$ & Intensify a fuzzy region & {$\left[\mu_{E I}(x)\right]^{3}$} \\
Very Important $(V I)$ & Contrast intensification & {$\left[\mu_{V I}(x)\right]^{2}$} \\
Fairly important $(F I)$ (i.e., no hedges) & - & {$\left[\mu_{F I}(x)\right]^{1}$} \\
\hline
\end{tabular}

Source: Cox [13]

\subsection{Simple Hierarchy Analysis}

Simple Hierarchy Analysis (SHA) method is the simplification of the Analytic Hierarchy Process (AHP) which was introduced by Saaty [14]. The SHA analyses specifically using the so-called direct evaluation approach without having a pair-wise comparison for each evaluated attribute. Thus, in this study we utlised the SHA-based linguistic hedges (see Table 1) to derive the importance of the relative weights for each criterion in the evaluation process

\subsection{The Proposed Method}

In order to clarify our proposed method, in this sub-section we will outline the step-by-step procedures as follows:

Step 1: Decompose the actual problem in the hierarchical structure to reveal different levels as depicted in Figure 1.

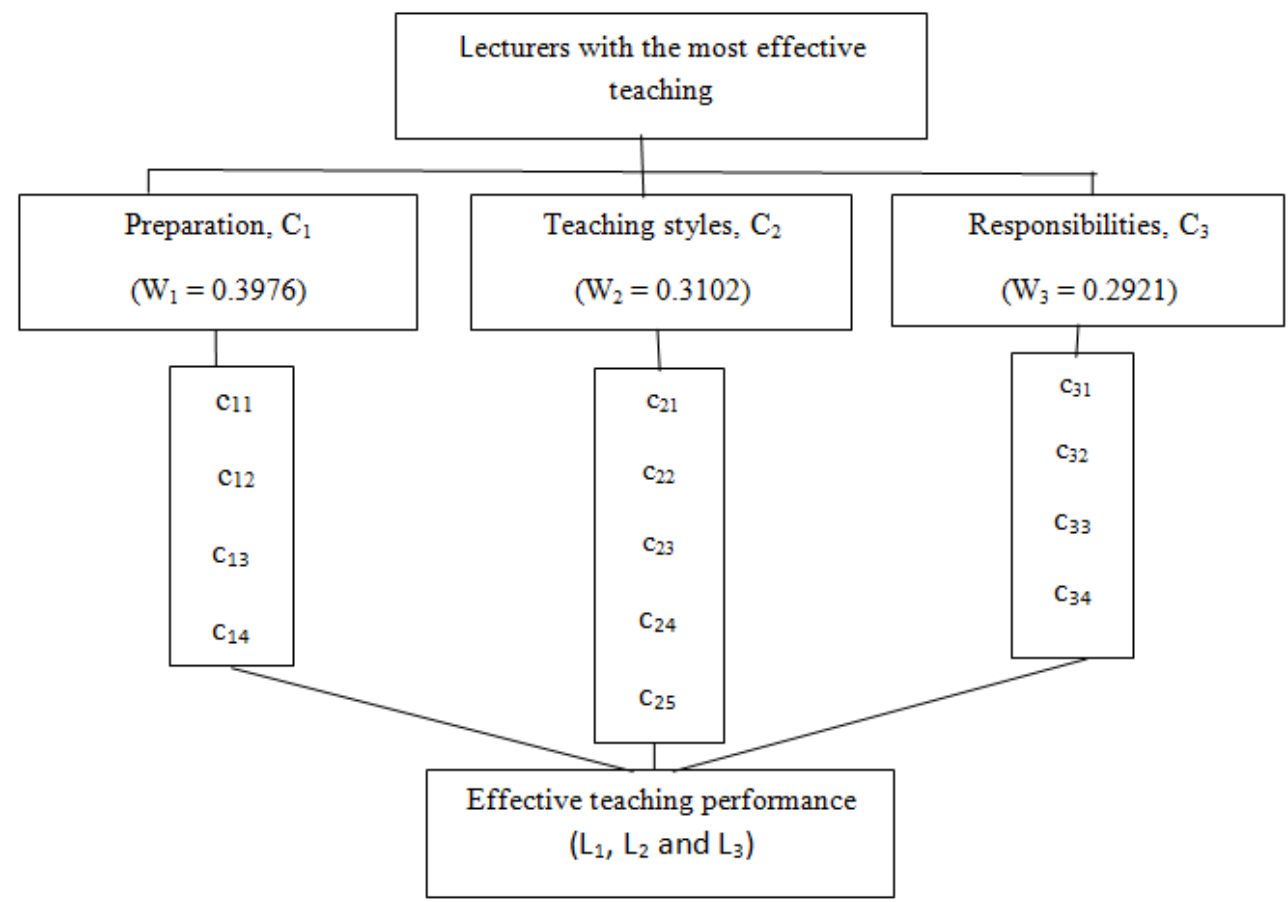

Figure 1: The hierarchical structure for evaluating effective teaching

Table 2: The mean of fuzzy numbers

\begin{tabular}{|c|c|c|c|c|c|c|c|}
\hline $\begin{array}{c}\text { Linguistic } \\
\text { variables }\end{array}$ & $\begin{array}{c}\text { Very poor } \\
(V P)\end{array}$ & $\begin{array}{c}\text { Poor } \\
(P)\end{array}$ & $\begin{array}{c}\text { Medium poor } \\
(M P)\end{array}$ & $\begin{array}{c}\text { Fair } \\
(F)\end{array}$ & $\begin{array}{c}\text { Medium } \\
\operatorname{good}(M G)\end{array}$ & $\begin{array}{c}\text { Good } \\
(G)\end{array}$ & $\begin{array}{c}\text { Very good } \\
(\text { VG })\end{array}$ \\
\hline $\begin{array}{c}\text { Mean of fuzzy } \\
\text { numbers }\end{array}$ & 0 & 0.17 & 0.33 & 0.50 & 0.67 & 0.84 & 1 \\
\hline
\end{tabular}

Step 2: Assign for each sub-criterion a corresponding criterion based on respondents' evaluation of each alternative using the mean of fuzzy numbers in Table 2 . The performance scores $\left(\tilde{P_{A L L}}\right)$ can be represented as 


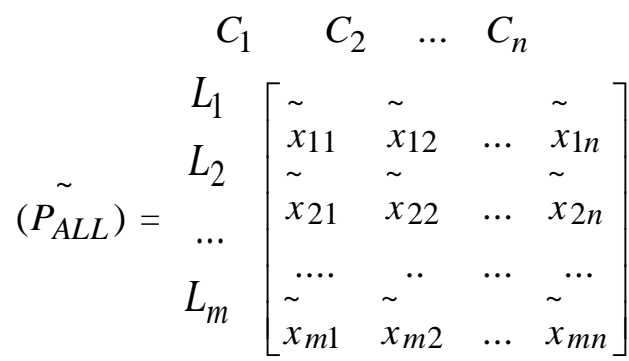

where, $\mathrm{C}_{i},(i=1,2,3, \ldots, n)$ is the number of criteria, and

$\mathrm{L}_{i}(i=1,2,3, \ldots, n)$ is the number of alternatives (i.e., lecturers)

Step 3: Calculate the total of all the scores for the weighted fuzzy decision matrix $\left(\tilde{P_{w A L L}}\right)$ as

$$
\left(\tilde{P_{w A L L}}\right)=\left[\left(W_{1}\right)\left[\begin{array}{c}
\tilde{x_{11}} \\
\tilde{x_{21}} \\
\ldots \\
\tilde{x m_{1}}
\end{array}\right]\left(W_{2}\right)\left[\begin{array}{c}
\sim \\
x_{12} \\
\tilde{x_{22}} \\
\ldots \\
\tilde{x_{m_{2}}}
\end{array}\right](\ldots)\left[\begin{array}{c}
\ldots \\
\ldots \\
\ldots \\
\ldots
\end{array}\right]\left(W_{n}\right)\left[\begin{array}{c}
\tilde{x_{1 n}} \\
\tilde{x_{2 n}} \\
\ldots \\
\tilde{x_{m \times n}}
\end{array}\right]\right] ; \text { and } \mu_{i}\left(\tilde{x_{j}}\right) \in[0,1]
$$

Step 4: Assign the power of concentration for each criterion based on DM's opinion as

$$
\tilde{D_{H}}=\left[\left(\begin{array}{c}
\mu_{11}(x) \\
\mu_{12}(x) \\
\ldots \ldots \\
\mu_{1 n}(x)
\end{array}\right)^{H_{1}}\left(\begin{array}{c}
\mu_{12}(x) \\
\mu_{22}(x) \\
\ldots \ldots \\
\mu_{2 n}
\end{array}\right)^{H_{2}}\left(\begin{array}{c}
\ldots \ldots . \\
\ldots \ldots . . \\
\ldots \ldots . . . \\
\ldots \ldots . .
\end{array}\right)^{H_{n-1}}\left(\begin{array}{c}
\mu_{1 n}(x) \\
\mu_{2 n} \\
\ldots \ldots \ldots . . \\
\mu_{m \times n}
\end{array}\right)^{H_{n}}\right]
$$

Step 5: Identify the best alternative by maximizing the minimum membership value for the overall criteria using Eq.-(6) given as

$$
\mu_{\tilde{D}_{H}}\left(x_{i}\right)=\max _{i}\left(\min _{j} \mu_{i j}^{w_{j}}\right)
$$

\section{Implementation}

To demonstrate how our proposed method is applied, a case study from Nora et. al. [1] has been adopted. The study was conducted for postgraduate students at Universiti Kebangsaan Malaysia (UKM). The questionnaire was designed to gather information on criteria or factors that influence students' evaluation of their lecturers. To illustrate this let us assume that the university wants to identify the lecturer who has been teaching most effectively based on the students' perspective, namely $\mathrm{L}_{1}, \mathrm{~L}_{2}, \mathrm{~L}_{3}$, and that the entire evaluation process is done with integrity. Thus, the information depicted in Table 3 is the summary of the selected and identified criteria and sub-criteria which comprise 3 and 13, respectively. Here, we employ the step-by-step procedures as elaborated in the previous section as follows:

Step 1: Decompose the actual problem in the hierarchical structure into three levels as shown in Figure 1.

Step 2: Assign to each sub-criterion a corresponding criterion based on the respondents' evaluation of each

lecturer using Table 2. Here, we will obtain the overall performance score $\left(P_{A L L}\right)$ from Eq.-(3) as,

$$
\tilde{P_{A L L}}=\left[\begin{array}{ccc}
M & G & V G \\
G & V G & V G \\
V G & V G & G
\end{array}\right]=\left[\begin{array}{ccc}
0.67 & 0.84 & 1 \\
0.84 & 1 & 1 \\
1 & 1 & 0.84
\end{array}\right]
$$


Table 3: The criteria and sub-criteria

\begin{tabular}{l|l|l}
\hline \multicolumn{1}{|c}{ Preparations $\left(\mathbf{C}_{1}\right)$} & \multicolumn{1}{c}{ Teaching styles $\left(\mathbf{C}_{2}\right)$} & \multicolumn{1}{c}{ Responsibility $\left(\mathbf{C}_{3}\right)$} \\
\hline $\begin{array}{l}\text { The lecturer is well prepared } \\
\text { in conducting lectures }\left(\mathrm{c}_{11}\right)\end{array}$ & $\begin{array}{l}\text { The lecturer possesses } \\
\text { confidence in delivering his/her } \\
\text { lecture }\left(\mathrm{c}_{21}\right)\end{array}$ & $\begin{array}{l}\text { The lecturer is interested in the } \\
\text { students' achievement and gives } \\
\text { feedback to the class }\left(\mathrm{c}_{31}\right)\end{array}$ \\
\hline $\begin{array}{l}\text { The lecturer gives a } \\
\text { framework of teaching at the } \\
\text { beginning of each lecture }\left(\mathrm{c}_{12}\right)\end{array}$ & $\begin{array}{l}\text { The lecturer delivers his/her } \\
\text { lectures with great interest }\left(\mathrm{c}_{22}\right)\end{array}$ & $\begin{array}{l}\text { The lecturer can be easily } \\
\text { contacted / met outside lecture } \\
\text { hours }\left(\mathrm{c}_{32}\right)\end{array}$ \\
\hline $\begin{array}{l}\text { Assignments given are related } \\
\text { to the course contents }\left(\mathrm{c}_{13}\right)\end{array}$ & $\begin{array}{l}\text { Important information is } \\
\text { repeated and emphasized }\left(\mathrm{c}_{23}\right)\end{array}$ & $\begin{array}{l}\text { The lecturer is punctual to class } \\
\left(\mathrm{c}_{33}\right)\end{array}$ \\
\hline $\begin{array}{l}\text { The lecturer is prepared to } \\
\text { answer questions }\left(\mathrm{c}_{14}\right)\end{array}$ & $\begin{array}{l}\text { The lecture is clearly delivered } \\
\left(\mathrm{c}_{24}\right)\end{array}$ & $\begin{array}{l}\text { The class is not canceled without } \\
\text { any reason }\left(\mathrm{c}_{34}\right)\end{array}$ \\
\hline & $\begin{array}{l}\text { Various examples and } \\
\text { illustrations are given }\left(\mathrm{c}_{25}\right)\end{array}$ & \\
\hline
\end{tabular}

Source: Nora et al. [1]

Step 3: Calculate the total of all the scores for the weighted fuzzy decision matrix $\left(P_{w A L L}^{\sim}\right)$ from Eq.-(4) as,

$$
\begin{aligned}
\left(P_{w A L L}^{\sim}\right) & =\left[(0.3976)\left(\begin{array}{c}
0.67 \\
0.84 \\
1
\end{array}\right)(0.3102)\left(\begin{array}{c}
0.84 \\
1 \\
1
\end{array}\right)(0.2921)\left(\begin{array}{c}
1 \\
1 \\
0.84
\end{array}\right)\right] \\
& =\left[\begin{array}{lll}
0.266 & 0.261 & 0.292 \\
0.334 & 0.310 & 0.292 \\
0.398 & 0.310 & 0.245
\end{array}\right]
\end{aligned}
$$

Step 4: Assign the power of concentration for each criterion $\left(D_{H}\right)$. Here we assume that all DM's have agreed that the preparation $\left(\mathrm{C}_{1}\right)$, the teaching styles $\left(\mathrm{C}_{2}\right)$, and the responsibility $\left(\mathrm{C}_{3}\right)$ criteria be categorized as "Extremely important" (EI), "Very important" (VI), and "Fairly important" $(F I)$, respectively. Hence, from Eq.(5) we have

$$
\begin{aligned}
\tilde{D_{H}} & =\left[\left(\begin{array}{l}
0.266 \\
0.334 \\
0.398
\end{array}\right)^{3}\left(\begin{array}{l}
0.261 \\
0.310 \\
0.310
\end{array}\right)^{2}\left(\begin{array}{l}
0.292 \\
0.292 \\
0.245
\end{array}\right)\right] \\
& =\left[\begin{array}{lll}
0.019 & 0.068 & 0.292 \\
0.038 & 0.096 & 0.292 \\
0.063 & 0.096 & 0.245
\end{array}\right]
\end{aligned}
$$

Step 5: Following the steps above, we can easily identify the best alternative using Eq.-(6). Thus, it is apparent that the third lecturer $\left(\mathrm{L}_{3}=0.063\right)$ has the maximum membership values, followed by the second lecturer $\left(\mathrm{L}_{2}=\right.$ $0.038)$, and finally the first lecturer $\left(\mathrm{L}_{1}=0.019\right)$. It is therefore concluded that the third lecturer $\left(\mathrm{L}_{3}\right)$ is the one with the most effective teaching.

\section{Conclusion}

In this paper, we have shown the application of the SHA method based on the variable weights. The method is equipped with the concept of weighted in fuzzy decision matrix and the insertion the power of concentration element for each criterion from the perspective of DM's, respectively. We believe that the proposed method is highly beneficial to the evaluation process. In addition, it takes away the complexity that is encountered in the calculation process. This helps to speed up the process by reducing the time spent on the analysis stages. It is also an extremely significant approach to fuzzy environment which utilizes membership values in the range of $[0,1]$ throughout the entire procedure. Although the given numerical example may be 
relevant only to this case study, we can expect similar outcomes for other cases. Furthermore, the proposed method has a unique advantage in the sense that it can distinguish clearly between every single judgment made by the respondents and the DM's. Finally, it offers a versatile judgment, is clear in procedures and successful in dealing with both perspectives (i.e., students' and university's requirements) which are diversified and too illdefined in terms of input criterion. Thus, the proposed method can assist the universities' DM's by facilitating the evaluation of lecturers in a simple and systematic manner. As a follow up, our next target is to formulate a new approach using the fuzzy Delphi method (FDM) in ensuring an effective teaching evaluation. This initiative will be the subject of our future research endeavour.

\section{Acknowledgements}

This research supported by RAGS grant from Ministry of Higher Education (MOHE) Malaysia, reference number: 600-RMI/RAGS 5/3 (148/2014) and Universiti Teknologi MARA, Malaysia. Also the authors would like to acknowledge the contribution of the reviewers in giving constructive comments and suggestions which have helped us improve the content of this work.

\section{References}

[1] M. Nora, B. S. Humaida, M. Noriza, M. A. Khairul Anuar, and I. Wan Rosmanira, Students perspective on lecturers characteristic for effective teaching, Procedia - Social and Behavioral Sciences, 59, 2012, 535- 540.

[2] H. Francisco, L. Enrique, M. Cristina, and A. R. Miguel, Solving an assignment-selection problem with verbal information and using genetic algorithms, European Journal of Operational Research, 119, 1999, 326 - 337.

[3] G. Zulal, S. L. Gurkan, E. K. Saadettin, A fuzzy AHP approach to personnel selection problem, Applied Soft Computing, 9,2009, $641-646$.

[4] R. L. J. Francisco, O. Lauro, and C. R. C. Luiz, A comparison between Fuzzy AHP and Fuzzy TOPSIS methods to supplier selection, Applied Soft Computing, 21, 2014, $194-209$

[5] K. Alecos, E. Kostas, and A. Dimitrios, Support managers' selection using an extension of fuzzy TOPSIS, Journal Expert Systems with Applications : An International Journal, 38, 2011, $2774-2782$.

[6] K. D. Kaveh, S. N. Soheil, and T. Madjij, Solving multi-period project selection problems with fuzzy goal programming based on TOPSIS and a fuzzy preference relation, Information Sciences, 252, 2013, $42-61$.

[7] S. Babak, R. V. Iman, T. Kaveh, and F. Safar, An exploratory analysis of hotel selection factors : A comprehensive survey of Tehran hotels, International Journal of Hospitality Management, 31, 2012, 96 - 106.

[8] T. Zamali, W. D. T. Nowyannie, N. Nasrah, and C. S. Tammie, Tourist arrivals to Sabah by using Fuzzy Forecasting, Presented in $4^{\text {th }}$ International Conference of Tourism Research (4thICTR), Organized by UiTM Sabah and USM, Sutera Harbour Hotel, Kota Kinabalu Sabah, Malaysia, 2014, 10 - 11 Dec.

[9] T. N. Huu, Z. M. D. Siti, N. Yusoff, and A. Hideki, A hybrid approach for fuzzy multi-attribute decision making in machine tool selection with consideration of the interactions of attributes. Expert Systems with Applications, 41, 2014, 3078 - 3090.

[10] E. Hikmet, O. Selami, and K. Kazim, Retail store location selection problem with multiple analytical hierarchy process of decision making an application in Turkey, Procedia - Social and Behavioral Sciences, 58, 2012, 1405 - 1414.

[11] N. I. Norddin, K. Ibrahim, and A. H. Aziz, Selecting new lecturers using the Analytical Hierarchy Process (AHP), Statistics in Science, Business and Engineering (ICSSBE), IEEE conference publications, 2012, 1 - 7.

[12] G. Ray, and S. Jennifer, Decision making in academia: A case of the dean selection process, Mathematical and Computer Modelling, 46, 2007, 1030 - 1040 .

[13] E. Cox, The fuzzy system handbook (New York, Academic Press, 1994)

[14] T. L. Saaty, The Analytic Hierarchy Process, (New York, McGraw-Hill, 1980). 